\title{
Máscaras ao rosto e tampões à boca: implicações na voz para a performance do professor que canta
}

\author{
VIEIRA, Márlon Souza \\ Universidade Estadual Paulista - Instituto de Artes \\ marlonsvieira@gmail.com \\ MIGUEL, Fábio \\ Universidade Estadual Paulista - Instituto de Artes \\ In memoriam
}

\begin{abstract}
Resumo: Neste trabalho, propõe-se discutir as interferências causadas à voz do professor, nesse momento de pandemia e isolamento social, em que instituições educativas têm buscado soluções para essa nova realidade. Neste cenário, considera-se que a performance do professor tem sido afetada e que os processos pedagógicos, que tem a voz como elemento comunicativo fundamental, encontram-se prejudicados em seus objetivos. De igual modo, avalia-se ser fundamental conhecer as estruturas e os aspectos formativos da voz: elementos que geram a ação performática do "professor que canta". Portanto, busca-se refletir como a voz é importante para o educador e, igualmente, ao olhar o prejuízo imposto à capacidade performática nessa atualidade, conscientizar-se a respeito de como deverá se comportar, quando for estabelecido a normalidade.

Palavras-chave: Voz, Performance, Prática docente, Pandemia, Educação Musical.
\end{abstract}

\section{Masks to the face and caps to the mouth: implications in the voice for the performance of the teacher who sings}

Abstract: In this paper, it is proposed to discuss the interferences caused to the teacher's voice, in this moment of pandemic and social isolation, in which educational institutions have sought solutions to this new reality. In this context, it is considered that the teacher's performance has been affected and that the pedagogical processes, which have the voice as a fundamental communicative element, are impaired in their objectives. Likewise, it is evaluated to be fundamental to know the structures and formative aspects of the voice: elements that generate the performance action of the "singing teacher". Therefore, we seek to reflect how important the voice is for the educator and, equally, by looking at the damage imposed on performing capacity in this day, to become aware of how normality is to behave when normality is established.

Keywords: Voice, Performance, Teaching Practice, Pandemic, Music Education.

\section{Introdução}

O ano de 2020 será inesquecível na trajetória histórica da Humanidade. Diferentes instituições econômicas, sociais, culturais e educacionais que, quase sempre, foram consolidadas no seu modo de atuação, foram, de certa forma, afetadas. É claro! Referimo-nos à Pandemia do COVID-19 e todas as suas consequências imediatas: isolamento social, quarentena, combate ao Novo Coronavírus, dentre outros. As consequências impostas à sociedade pela pandemia no mundo e no Brasil, são nefastas. O Brasil atinge (em 08/01/2021), mais de 200 mil mortos pela COVID-19. Mortos que são sepultados sem que seus entes queridos possam lhes dar o último adeus. A partir de janeiro de 2021, inúmeras famílias não receberão mais o auxílio emergencial que lhes garantia o sustento básico. Os brasileiros e 
brasileiras se sentem desamparados em meio a um desgoverno que tem feito dessa crise sanitária, um terrível palco de disputa política. Estamos vivendo uma crise sanitária com prejuízos sociais, culturais, educacionais e econômicos sem precedentes. Nesse momento as desigualdades sociais ficam ainda mais acentuadas. Pobres ficam ainda mais pobres e ricos ficam cada vez mais ricos.

Ao olhar para a escola, observam-se drásticas transformações que, neste momento epidemiológico, acentuam e ampliam os problemas de momentos anteriores. Do ensino básico ao ensino superior, professores e alunos tiveram que se adaptar à nova realidade de ensino remoto. Pode-se dizer que essa adaptação não foi e não tem sido um processo tranquilo, pois não estávamos preparados para isso. Mudanças na educação precisam ser feitas com a ampla participação da comunidade e essas transformações precisam ser geradas com base em reflexões muito profundas. Não existem soluções imediatistas para a educação. Como bem colocou o professor Lalo Watanabe Minto", há uma "falsa polarização quando se coloca o ensino remoto e à distância como soluções inovadoras para esses tempos". Para os estudantes de escolas e universidades públicas a situação ficou ainda mais complexa, pois muitos não tinham acesso a uma internet de qualidade que lhes possibilitasse participar das aulas. Vários discentes, também, tiveram que dar suporte financeiro, emocional, entre outros, aos mais idosos de suas famílias. As salas vazias, as aulas remotas e as videoconferências são reflexos que modificaram o tradicional jeito da educação e, principalmente, do professor. Acostumado a utilizar a voz ativamente e em distintos momentos performáticos ${ }^{2}$ como meio para se fazer ouvir pelos alunos, ocupantes das salas de aulas - ressalta-se que na realidade brasileira são salas cheias -, agora, nesse novo cenário, esse elemento tão importante que é a voz, tenha passado a estar em condição passiva, ao menos, quando se trata das questões referentes aos impedimentos causados pelas máscaras e aos novos formatos tecnológicos em que ocorrem as aulas.

No caso do professor que atua com música, acentuam-se, com maior potência, essas implicações referentes ao uso da voz. O professor de música que utiliza a voz como um dos meios mais eficazes para o desenvolvimento de habilidades requeridas pelo "chão" das aulas

\footnotetext{
${ }^{1}$ Frase extraída de uma live promovida pela ADUNESP (Associação dos Docentes da UNESP) em 05/06/2020 intitulada: PANDEMIA E UNIVERSIDADE PÚBLICA - Educação, ensino e condições de trabalho e está disponível em: https://www.youtube.com/watch?v=7CKjN2vp5EY\&feature=youtu.be.

${ }^{2}$ Para esse texto, concebe-se o termo performance a qualidade do uso da voz em sua capacidade de, pelo som, representar de modo pleno e sistemático as demandas requisitadas pelo corpo, o que Paul Zumthor (2007) descreve como "emanação do corpo".
} 
de música padece com o atual cenário. Aquele docente que estava sempre cantando ou solfejando partituras com seus alunos, agora, encontra-se impedido pelas tecnologias usadas, que são limitadas para tal atividade. Já o educador que, por vezes, precisava "levantar" a sua voz para acalmar a turma, agora não o faz mais, pois todos os microfones virtuais podem ser silenciados durante as videoconferências. A continuidade e a constância do uso da voz para aqueles professores que davam aulas seguidas e durante grande parte do dia, no atual cenário, também foram, de alguma forma, interrompidas. Sabe-se que houve, por parte das escolas e universidades, flexibilizações quanto aos horários e aos procedimentos didáticos, enquanto outros sistemas educacionais ainda estão definindo como será o retorno das aulas, ou seja, na situação apontada, o professor está com a sua voz em pausa. Com isso, fica uma questão: como a voz se comportará quando houver o retorno das aulas presenciais? Uma coisa é muito provável, o uso de máscara pelos professores e estudantes perdurará, ao que parece, por longo tempo, mesmo depois que a vacinação iniciar no Brasil. A voz do professor passará por um longo período de readaptação quando do retorno das atividades presenciais, pois durante os tempos de isolamento social, a voz tem estado confinada. Precisaremos reaprender a projetar a nossa voz no ambiente da sala de aula.

Destacamos, então, que essa pandemia tem servido para mostrar o quão importante é a voz; como o seu uso se modifica quando os momentos experienciados são diferentes e como utilizamos constantemente a voz performaticamente. Em meio ao isolamento social a voz tem sido, para muitos, o único meio de conexão - seja por meio de videoconferências, chamadas de vídeo pelo WhatsApp, uso de plataformas como Zoom e Hangouts Meet.

Nesse cenário, compreende-se como a voz é importante para aqueles que a consideram ferramenta principal de seu trabalho. Esta investigação, portanto, observa o quão comprometida pela voz está a performance, dado que o aparelho vocal possui impressão individual e personalidade (SCHAFER, 2011b).

A pandemia nos comunica que devemos estar atentos à nossa saúde vocal. Manter, durante a pandemia, os cuidados com a voz nos ajudam a prevenir alterações vocais, bem como a manutenção de sua qualidade. A condição geral de saúde de uma pessoa pode interferir positivamente ou negativamente em sua voz. Muitos indivíduos usam sua voz falada mais aguda ou mais grave do que deveriam, o que pode acarretar desgaste vocal. De maneira geral, recomenda-se uma boa hidratação, alimentação adequada, sobretudo para evitar o refluxo gastroesofágico que pode ser nocivo às pregas vocais; outro ponto a considerar é não usar 
medicamentos sem antes consultar um médico, não utilizar cigarro e bebida alcóolica, não falar em lugares barulhentos onde as pessoas acabam aumentando o volume da voz para transpor, de alguma maneira, os ruídos presentes. É importante, ainda, repousar a voz, sobretudo em casos de crises alérgicas acentuadas e cuidar da qualidade do sono, evitar ficar exposto ao arcondicionado e tomar cuidado com as mudanças bruscas de temperatura ${ }^{3}$. Muitos professores, no começo da pandemia, se queixaram de cansaço vocal em função das aulas remotas. Alguns perceberam que o desgaste se deu pelo aumento da intensidade da voz durante as aulas virtuais. A mudança de meio trouxe implicações na percepção do volume adequado da voz para falar e cantar. Por isso, conhecer e compreender os processos formativos da voz é de suma importância aos professores, pois é dela e por ela que se alicerça a trajetória profissional da carreira docente. O conhecimento da voz permite que o professor a utilize com maior eficiência e, também, preserve a sua saúde vocal. A voz é um elemento fundamental na comunicação entre professor e aluno, mostra-se essencial para a viabilização da atividade docente. Assim, conhecer e compreender os limites e as qualidades para que haja uma ação pedagógica efetiva e dinâmica se faz relevante, principalmente, ao professor de música que utiliza a voz para o desenvolvimento de habilidades requeridas para as aulas.

\section{O uso da voz: pregas vocais, timbre e registro}

O uso da voz por um professor em sala de aula é repleto de demandas: grita ou fala alto para dar uma ordem; para isso, a usa de modo incisivo; fala baixo e suavemente, quando quer obter atenção total da classe; para tanto, fala melodiosamente; rápida, ou lentamente; por etapas, ou constantemente. Lembramos, ainda, que a voz sofre interferências do estado de humor do indivíduo.

De acordo com Sundberg (2015, p. 202-203) encontramos elementos que nos remetem ao estado de humor do falante no contorno melódico de um enunciado, no padrão respiratório, na intensidade e frequência de fonação. Ou seja, o autor conclui que há uma relação entre estados emocionais e padrões de movimentos fonatórios e articulatórios (SUNDBERG, 2015, p. 214). É possível perceber o estado de humor do falante baseado apenas no som de sua fala, mesmo que não se compreenda o que é dito, não se conheça aquele que fala e sequer pertença

\footnotetext{
${ }^{3}$ Outras informações relacionadas aos cuidados com a voz poderão ser encontradas em livros, como por exemplo, PINHO, Silvia M. R. Manual de higiene vocal para profissionais da voz. 3 ed. Carapicuíba, SP: Pró-fono, 2002.
} 
à mesma cultura do falante. $\mathrm{O}$ estado de humor, portanto, influencia o comportamento vocal (SUNDBERG, 2015, p. 215-216).

Por exemplo, o professor que está bravo por alguma razão, tenderá a elevar o volume de sua voz, além da emissão ser mais tensa; ao contrário daquele que está mais tranquilo, cuja voz será emitida com um volume mais baixo. Pode-se relacionar esses tipos de expressão vocal aos ambientes em que ocorrem as aulas, uma relação pertinente: em sala grande ou pequena; em espaço aberto ou fechado; em ambiente com ar-condicionado, ventilados, ou não ventilados; em ambiente gelado ou quente. Ainda, quanto ao uso da voz, é possível observar algumas questões fisiológicas: fala logo cedo, quando o indivíduo acorda ou, ao final do dia, depois de muito ter falado; ou quando está rouco, fanho ou, ao contrário, em perfeitas condições; ou, ainda, quando gripado, ou saudável. Considera-se que todas essas ações que envolvem o homem e o uso da voz são deliberações performáticas próprias do ambiente em que está inserido. O cotidiano da voz de um professor, imbricado à audição, torna-se emissário de possibilidades representativas para um profícuo e proveitoso ambiente, neste caso, a sala de aula. Schafer destaca que "a voz humana, em conexão com o ouvido, deve fornecer os referenciais para as discussões sobre o ambiente acústico saudável à vida" (SCHAFER, 2011b, p. 195).

Percebe-se, além disso, que as questões do uso da voz pertinentes aos docentes são inúmeras e, nesse contexto, entender sua utilização nesses diferentes cenários é de fundamental importância. Para compreender essas ações, em especial quando inseridas no cotidiano da carreira docente, em que ele reflete a respeito do desempenho vocal antes, depois e enquanto leciona, inicialmente, se faz necessário priorizar a identificação dos termos e sentidos referentes a ela. Assim, poder-se-á propor conscientemente base conceitual para as discussões aqui propostas.

Inicia-se, então, com a tentativa de esclarecer o que é a voz. A partir do enfoque físico, a voz é o som emitido por meio da vibração das pregas vocais, modificado pelas cavidades de ressonância, durante uma expiração. Nessa engrenagem, as pregas vocais vibram depois que o fluxo e a pressão de ar são ativados pelo sistema respiratório (BEHLAU, 2001).

Dito de outra forma, a voz é produzida a partir de um som básico gerado na laringe, chamado fonação. A laringe localiza-se no pescoço e é um tubo composto por cartilagens. Dentro da laringe estão as pregas vocais, as quais são responsáveis pela produção da matéria prima sonora. Elas são duas e estão paralelas ao solo, como se estivessem deitadas. O tamanho 
e espessura das pregas vocais variam de acordo com a idade e o sexo da pessoa. Por exemplo, um adulto com pregas vocais maiores e mais espessas, tenderá a ter uma voz mais grave, já o indivíduo com pregas vocais menores e menos espessas, poderá apresentar uma voz mais aguda.

As pregas vocais afastam-se para que o ar entre nos pulmões e aproximam-se e vibram para que a fonação aconteça. Portanto, o ar é essencial para a produção da voz, sendo o combustível energético da fonação. Sem o ar não seria possível ativar a vibração das pregas vocais, o que você pode comprovar fechando a boca e o nariz simultaneamente e procurando emitir um som. Sendo o ar elemento vital para que a voz seja produzida, é curioso observar que justamente a infecção gerada pelo Sars-CoV-2 atue, entre outros pontos, na limitação da capacidade respiratória do infectado, pelo comprometimento do pulmão.

No entanto a principal função da laringe não é produzir a voz, mas sim proteger as vias respiratórias, sobretudo os pulmões. O som na laringe é semelhante ao de um barbeador elétrico, não sendo parecido com nenhuma vogal ou consoante. Pode-se também imitar esse som, vibrando os lábios. O som básico produzido pelas pregas vocais na laringe passa por uma série de cavidades de ressonância, que se ajustam como se fossem um alto-falante natural formado pela própria laringe, faringe, boca e nariz.

Com isso pode-se compreender que a voz é resultado do equilíbrio entre duas forças - a força do ar que sai dos pulmões - a chamada força aerodinâmica, e a força muscular das pregas vocais - a chamada força mioelástica. Caso haja um desequilíbrio nesse mecanismo, poderá acontecer uma alteração vocal. Se o ar que passa pela laringe é excessivo, a voz será soprosa ouvindo-se "ar" na emissão, uma queixa muito comum entre cantores, professores e outros profissionais da voz. Por outro lado, se a força muscular for maior que a necessária, o som ficará comprimido em pouco ar e a voz sairá tensa e estrangulada.

Os sons são articulados principalmente na boca, através de movimentos da língua, dos lábios, da mandíbula, dos dentes e palato. A voz falada e cantada utiliza-se das mesmas estruturas, com diferentes ajustes devido às necessidades do canto. Esses ajustes estão relacionados principalmente a maneira de respirar, que no canto é mais profunda. As pregas vocais vibram de maneira mais controlada e com maior energia acústica, as caixas de ressonância são amplamente empregadas para amplificar o som básico produzido na laringe.

Dessa maneira, a voz pode ser entendida como uma variedade de sons emitidos por estruturas especificamente destinados a produzi-la, como, por exemplo as pregas vocais. Reiterando, as pregas vocais são estruturas musculares muito delicadas que são ativadas pelos 
músculos intrínsecos (internos) e extrínsecos (externos). Os músculos intrínsecos atuam na abertura, fechamento, alongamento e tensão das pregas vocais. Os extrínsecos agem no abaixamento e levantamento da laringe, que é o órgão onde as pregas vocais estão abrigadas. Quanto mais agudo o som emitido mais alongadas e tensas as pregas vocais estão. Nos sons mais graves as pregas vocais ficam mais frouxas e menos tensas. Encontram-se entre esses sons, o gritar, o chorar, o gargalhar e o gemer. Quando organizados segundo algumas regras de uso, constroem a fala e o canto.

Os sons gerados pelo órgão vocal, incluindo as pregas vocais vibratória; ou, mais precisamente, por uma coluna de ar originada pelos pulmões, modificada em primeiro lugar pelas pregas vocais vibratórias e, depois, pelo resto da laringe, faringe, boca e, às vezes, também, pelas cavidades nasais. Assim, a voz se torna sinônimo de som vocal (SUNDBERG apud DAVINI, 2008, p. 308).

Nesse contexto, quando a voz assume a condição de fala, alcança também a condição de código comunicativo para os indivíduos e torna-se importante para as relações dialógicas e interlocutoras da humanidade. É nesse processo que vemos o som da voz como o mais significativo para o homem; é por meio dela que ocorre a consolidação e o pertencimento de interação no mundo. Rodrigues et al., destaca que

Todos os sons humanos são potencialmente expressivos de vida, mas o som da voz, presumivelmente devido à sua notável variabilidade minuciosamente controlável e ao seu caráter pessoal, é, com certeza, o mais importante deles (Rodrigues et al, 2013, p. 129).

Linklater (1976) define a voz como um instrumento humano; isso porque, no cotidiano, a voz se torna elemento representativo da pessoa. Segundo essa autora "[...] se no dia-a-dia a voz expõe a pessoa, a voz como instrumento tenderia a funcionar, paradoxalmente, como uma tela cuja função seria a de ocultar a pessoa” (Linklater, apud DAVINI, 2008, p. 309).

Percebe-se, assim, que a voz ganha uma identidade, o que é conhecido como timbre. O timbre vocal é um elemento distintivo, não há uma voz igual a outra. Cada voz tem a sua característica sonora, sua individualidade, aspectos que a torna única. O timbre da voz está relacionado à sua cor que pode ser clara ou escura e, isto, na realidade é determinado pela quantidade e intensidade de harmônicos que a voz possui. Pensando acerca da identidade vocal de modo mais amplo, concordamos que nossa identidade vocal é constituída na trajetória de nossa vida, levando em conta nossa história, os nossos relacionamentos interpessoais e a nossa forma de nos comunicar uns com os outros (BEHLAU et. al, 2017, p. 17). Timbre é a qualidade daquilo que produz som. É a característica específica do som, o que permite que a fonte emissora seja reconhecida pelo ouvinte; pode ser o som de uma voz ou de um instrumento 
musical ${ }^{4}$. É assim que surgem algumas características vocais consagradas no senso comum: voz sexy, voz chata, voz agradável, voz de locutor, voz de "taquara rachada", voz infantil, dentre outras.

Alinhado com o timbre, há outro conceito necessário para compreender a voz: o registro. Diferente do timbre, o registro é um conceito associado prioritariamente à voz humana. Referese a extensão vocal permitida pela vibração das pregas vocais que entrelaçam a voz grave e a voz aguda. A percepção dos diferentes registros vocais contribui para a exploração de diferentes sonoridades da voz, seja no contexto da fala ou do canto. Por exemplo, quando falamos de modo enérgico, contundente, empregamos o que é chamado de registro de peito, que resulta numa voz mais densa, encorpada; quando falamos suavemente, em geral, utilizamos o que é denominado registro de cabeça, com uma sonoridade mais leve e menos encorpada. Isto é, nas diferentes situações do cotidiano ou da sala de aula, o registro vocal será solicitado de diferentes maneiras em função do trabalho de grupos músculos intrínsecos laríngeos específicos. A literatura aceca do assunto, aponta que no registro de peito, há predomínio de atividade do músculo intrínseco, denominado TA (Tireoaritenóideo) e no registro de cabeça, o CT (Cricotireóideo). O primeiro é constituído com maior proporção de fibras de contração rápida, o que os torna mais fatigáveis. O segundo é formado com maior proporção de fibras de contração lenta, o que os torna mais resistentes (PINHO e PONTES, 2008, p. 62-64). A partir dessa informação, concluímos que na voz falada ou cantada o uso inadequado do registro de peito, pode ocasionar alterações e desgastes vocais. Essa consideração pode ser corroborada se observarmos que, por muitas vezes, quando as pessoas ficam roucas elas começam a perder a voz pela região grave, a qual abarca o registro de peito. Ao estudar o registro com a finalidade de encontrar semelhanças e diferenças conceituais que perpassam por distintas perspectivas vocais, tais como: "cantor(a)/professor(a) de canto; fonoaudiólogo(a) e otorrinolaringologista; ou cientista da voz" (MIGUEL, 2012a, p. 28) identificamos que cada um desses profissionais percebe que a ampliação da definição do registro vocal busca compreender os diferentes modos de perceber a qualidade e o uso da voz:

[...] que têm buscado por diversos meios e técnicas compreender na voz humana, quais são os princípios fisiológicos que regem uma gama de sons que vão do grave ao agudo, guardando uma natureza sonora peculiar a cada região, que se evidenciam operacionalmente por meio dos elementos: perceptivos, acústicos, fisiológicos e aerodinâmicos, essenciais à configuração do fenômeno registro vocal, [...] (MIGUEL, 2012a, p. 34-35).

\footnotetext{
${ }^{4}$ Segundo o Dicionário de Música organizado por Alan Isaacs e Elizabeth Martin (1985), Timbre é a qualidade ou a cor do som. "É determinado pelo número e intensidade dos harmônicos coexistentes com o som fundamental."
} 
Segundo Sundberg (1987), o registro refere-se à pronúncia ou aos modos da fala, que designam as peculiaridades do som, que se alteram conforme as origens social e geográfica das pessoas. Nesse contexto, com as resultantes advindas da relação timbre e registro, observa-se a capacidade performática da voz, que aparece, pontualmente, a partir da vontade e da intenção da emissão da voz e que possibilita estruturar o seu uso como força expressiva. Concordamos que “A emissão da voz é um fenômeno que comporta grandes variações. Além das consideráveis diferenças de uma pessoa para a outra, a voz apresenta-se em um mesmo indivíduo sob múltiplos aspectos" (HUCHE; ALLALI, 2005, p. 11).

Assim, quando condicionado por sua estrutura social, um professor manifesta, por meio de sua voz, nuanças, variações melodiosas e ondulações timbrísticas a ela. Esse processo se revela pelo uso do caráter expressivo da voz que, concomitantemente, pode ser entendido por deliberação performática da voz. Por intermédio de sua voz, o professor impacta o seu ouvinte e, ele é também, influenciado pelas vozes das pessoas com as quais se relaciona. Nesse sentido, compreendemos que a voz extrapola aspectos fisiológicos, revelando que a voz é conexão da mente do corpo e do espírito. Somos produto de nossa voz. Nossa voz faz parte de uma teia social.

\section{A voz como ação performática}

Ao compreender a voz como meio fundamental para a comunicação humana, pode-se constatar que ela está presente em todas as culturas, desde a Antiguidade. A voz é central em toda cultura e, assim do interior desse fenômeno poderemos vislumbrar o que esses sons vocais dizem a respeito de nós mesmos, do nosso modo de pensar, agir e se relacionar com o outro (ZUMTHOR, 2000, p. 13). A voz, sobretudo nesse momento de pandemia, tem exercido uma função centrípeta - isto é, tem proporcionado a aproximação das pessoas (SCHAFER, 2011a, p. 246). Desde tempos mais remotos as pessoas concebem ideias, concepções, sensações e sentimentos acerca da voz que produzem ou escutam, essas são as representações sociais a respeito da voz (MOSCOVICI, 2007). Nesse período de isolamento social essas representações têm sido formuladas, transformadas e adaptadas e isto nos permite pensar no caráter simbólico da voz que gera em nós emoções ou pensamentos, além das sensações mais imediatas que ela pode nos trazer (SCHAFER, 2011a, p. 239). A voz traz consigo a unicidade de quem a produz (CAVARERO, 2011, p. 17). Para essa experiência é preciso se ater à vocalidade que é definido como "o conjunto das atividades e dos valores da voz que lhe são próprios, independente da 
linguagem" (CAVARERO, 2011, p. 27). A voz expressa o que as palavras não conseguem expressar - a unicidade de quem a emite.

O entrelaçamento desses conceitos nos ajudam a pensar numa Antropologia da voz que nos permite conhecer o homem e suas relações com o outro e os seres vivos, por intermédio da voz que está presente nas mais diferentes culturas. Por isso, ao adentrarmos ao universo sonoro da voz que se estabelece em meio ao isolamento social podemos obter indicativos de como observar, analisar e interpretar as produções vocais e os significados que surgem em meio aos mais variados contextos (MIGUEL, 2012b).

Considerando-se que a humanidade, em sua trajetória de consolidação, além de usar a voz para se comunicar, por ela também se expressa, desempenha e atua, principalmente, em períodos específicos que geram trânsitos vocais, pode-se refletir que na voz humana encontrase fundamental capacidade performática. Assim, destaca Vilas:

O caráter histórico-social da voz, fundante do conceito de vocalidade, aplica
pensar a voz humana como um universal que se manifesta na particularidade
contingente e restrita de um determinado tempo-espaço. (VILAS, 2008, p. 281)

Da mesma forma, Paul Zumthor (2007, p. 27) considera "com efeito a voz, não somente nela mesma, mas (ainda mais) em sua qualidade de emanação do corpo e que, sonoramente, o representa de forma plena". Assim, do mesmo modo como os homens constituem representações entre si e nos entendimentos de como relacionam-se por meio da voz, em cada ato em que a voz é utilizada, a ação performática é efetivada. Em todas as deliberações humanas nas quais a voz é meio condutor, pode-se observar a concretização do uso performático da voz.

Quando aproximamos esses subsídios conceituais à realidade cotidiana do professor, percebe-se que ações simples ou complexas numa atuação docente, por serem carregadas de nuances vocais, emanam deliberações performáticas. A energia atribuída pelos momentos acalorados, próprios das tentativas de se fazer ser ouvido pelos alunos, quase sempre carregada de muita vontade e emoção, são elementos que sentenciam a atuação performática do professor.

Ainda no entendimento da voz como elemento performático, nota-se íntima relação desse processo com o locus inerente à atuação daquele que utiliza a voz. O contato das pessoas e suas experiências de vida com as dinâmicas próprias dos lugares com os quais os homens constroem sua existência, seja no aspecto material, seja no espiritual, perpassa as deliberações performáticas por meio da voz. Os rituais, os eventos sociais, as disputas de poder, os pertencimentos humanos dos saberes constituídos são carregados de produções vocais que geram performances, nos tempos e nos espaços que solidificam essas relações sociais. 
No caso da atividade docente, esse tempo e espaço é o cotidiano da sala de aula. O professor, em contato com os alunos, ao utilizar a sua voz ao dar sua aula, precisa estabelecer comunicação clara e concisa para fazer seu papel educacional. Em geral, esse processo é intermediado por símbolos e signos, convencionados ou eventuais, considerados, em sua totalidade, ações performáticas, que ajudam o professor, cantor ou performer a construir uma comunicação elaborada e eficaz. Denis Vasse afirma que "a voz se situa no espaço intermediário entre o orgânico e a organização, no intervalo entre o corpo biológico e o corpo social" (apud VILAS, 2008, p. 281). Nesse contexto, pode-se destacar que "As palavras deixam de ser signos duais dotados de significado e significante, de sentido e som para fundirem-se em uma só experiência simbólica [...]” (BORDELOIS, 2003, p. 92-93).

Essa pandemia, de certa forma, modificou a maneira pela qual as vozes dos professores são projetadas. A voz que no contexto presencial era projetada no corpo de quem produz, no espaço da sala de aula e reverberava em seus ouvintes, foi achatada numa tela de celular ou computador, filtrada pelos microfones de um ou outro dispositivo, além dos atrasos na chegada do som até o ouvinte, em função da qualidade de conexão da internet. Essa voz midiatizada não proporciona uma educação relacional em que professor e estudante se nutrem de saberes, afetos, experiências e amor. Nota-se isso quando nos referimos às aulas remotas, ou melhor, às videoconferências. Como quase sempre os alunos estão com as câmeras desligadas, não há condições e ações disparadoras para que o professor possa se manifestar do mesmo modo como o faz numa aula presencial, isto é, com "olho no olho" e "voz na voz". Não se sabe se há dúvidas, compreensão ou entendimento, por parte dos alunos. Fica faltando um elo nesse campo da comunicação. A passividade provocada pela atividade monóloga e cega do professor, modifica as questões performáticas da voz que, antes, era ativa e dinâmica, e agora, com a pandemia, tornou-se indiferente, ociosa e apática.

\section{Implicações para o professor que canta}

A utilização que o professor faz da sua própria voz mostra-se importante para que os objetivos didáticos sejam alcançados. Contudo, quando se refere ao professor de música, este uso da voz mostra-se intensamente mais acentuado. Fato é, que não podemos desconsiderar aqueles docentes que utilizam a música como meio para desenvolver suas dinâmicas no momento de ensinar; como exemplo, um professor de geografia que utiliza paródias em suas aulas. Entretanto, verifica-se que o professor de música tem a voz, e seu devido uso 
performático, como uma das ferramentas elementares e fundamentais para exercer a sua atividade em educação musical.

A construção do cantar, a educação musical e o desenvolvimento da performance se dão a partir de uma pedagogia relacional que possibilita ao professor de canto e ao educador musical proporcionarem situações em que os alunos participem ativamente, explorando a sua voz, descobrindo seu corpo, conhecendo melhor seu funcionamento e suas possibilidades (SPECH; BÜNDCHEN, 2012, p. 69).

Sabe-se que as aulas de música são repletas de práticas e dinâmicas que utilizam a voz. Igualmente, alguns teóricos confiam na voz como elemento principal para ensinar música. A professora Bernadete Zagonel (2012) afirma que:

A voz é o instrumento musical nato do ser humano, mas nem sempre os professores de música a utilizam em todo o seu potencial. [...]. É necessário, portanto, ver na voz um instrumento eficaz e cheio de possibilidades e recursos para a criação sonora (ZAGONEL, 2012, p. 18).

Já o educador musical Joaquim de Paula destaca que "Brincar com a voz é questionar, construir a própria identidade, experimentando momentânea e intencionalmente outra postura de ser perante o mundo" (PAULA, 2009, p. 13). Nesse contexto, por ser a voz um instrumento musical natural e acessível a todos os alunos, faz-se necessário que o professor de música dê conta dessa natureza fundamental para as aulas de música. Os resultados mais comuns desse desdobramento do uso da voz em sala de aula são as formações de grupos vocais e corais que se apresentam em festas e eventos pontuais da escola. Percebe-se, também, a descoberta de "talentos" - aqueles que por motivo anterior trazem dispositivos de afinação e rítmica, por exemplo -, que se destacam dentre o universo dos alunos; com frequência, são os que vêm de uma trajetória de envolvimento com o canto familiar, ou o canto na igreja.

Deste modo, o uso da voz na educação musical, além de ser equipamento indispensável, mostra-se, ainda, peça importante na engrenagem para o professor que canta, dado que constrói atividades que vão além da oralidade - um organismo que do mesmo modo é cognitivo.

Agora, na pandemia, esse processo encontra-se prejudicado. Canções em diferentes línguas, nas aulas de música em todo o planeta, recebem interferências em distintas situações universais. A vozes que frequentemente convertem nuanças em performances, passam a ser cúmplices de um dano da comunicação entre professores e alunos: vozes que cantam, calamse. O atual aparelhamento orientado pelas instituições que geram os sistemas de saúde que designam - com razão - o uso de máscaras, não previu os efeitos colaterais deste uso, que dentre inúmeros outros, trouxe implicações àqueles que utilizam a voz como seu mais precioso dispositivo. 
Isto fica evidente quando se observam as notícias e os relatos de professores de música que atuam em todo o planeta - entre os quais estes pesquisadores estão incluídos. Igualmente, quando se observa as vivências das atuais aulas remotas, a realização das atividades que envolve o canto, seja de modo individual ou coletivo, mostra-se intensamente prejudicada. Sobretudo, as atividades musicais que envolvem o canto coletivo tiveram que ser repensadas na pandemia. Em função da necessidade de distanciamento social os ensaios corais foram suspensos e muitos grupos passaram a realizar encontros virtuais, o que no começo parecia ser uma grande "novidade", mas que no decorrer dos meses se mostrou uma prática cansativa, para muitos.

A partir de março de 2020, começamos a ouvir diversos webinários, a ler reportagens e artigos científicos oriundos de várias partes do mundo que discutiam a respeito de como o ato de cantar poderia ser um grande fator de contaminação em função de gotículas e aerossóis disparados durante a emissão vocal. Começou-se, a essa época, criar um certo alarde de que o canto coletivo estava com os seus dias contados. Estudos realizados, na Alemanha, Áustria e Estados Unidos, ao longo do ano, trouxeram dados que mostraram que o ato de cantar, não é o "grande vilão" da pandemia. A partir de agosto, setembro, aproximadamente alguns grupos, em várias partes do mundo, inclusive no Brasil, começaram a retornar seus ensaios, envolvendo a voz, com protocolos rigorosos, abarcando o uso de máscara, distanciamento social, ensaios de curta duração, redução de pessoas por ensaio, ensaios ao ar livre ou em espaços grandes e com ventilação natural, entre outras medidas.

Estamos em janeiro de 2021 e não podemos dizer, exatamente, quando as atividades vocais coletivas retornarão à sua normalidade, sobretudo nos estabelecimentos de ensino público. Pensamos que, talvez, se houver vacinação no Brasil, no segundo semestre de 2021, podermos ter um retorno gradativo e parcial de atividades dessa natureza.

\section{Considerações finais}

$\mathrm{Na}$ construção da trajetória dos homens, desde a pré-história, diferentes crises humanitárias sempre estiveram presentes. $\mathrm{Na}$ atualidade - que tem por característica principal os modos de vivências pautados na globalização -, crises também acontecem, porém, muitas não são levadas em conta. Isso acontece porque, na concepção global moderna, a pressa, a correria e a agitação do cotidiano, em que a necessidade de dar conta das metas diárias e objetivos constantes, escondem essas adversidades. É nesse contexto que se vê pessoas dizendo: "Como os dias passam rápidos", ou "chegamos em dezembro e nem percebemos". Então, 
percebe-se que o homem só dá conta desses problemas e apuros quando ocorre um trauma. $\mathrm{O}$ choque causado pelo trauma o leva a repensar e a refletir acerca de suas práticas e de seus modos de vida.

Analogamente, é assim que se deve associar a crise da pandemia causada pelo COVID19. As atenções aos efeitos colaterais causados pelo isolamento social vêm traumatizando as performances dos professores que têm a voz como dispositivo básico e essencial, sobretudo, aqueles que desenvolvem atividades em aulas de música. Essa pandemia eclodiu, sinalizando em luzes amarelas as devidas atenções aos aspectos que envolvem a voz. Não apenas por ter modificado os momentos performáticos inerentes às salas de aula, que agora estão vazias e mudas, mas pelo grau de importância apresentado quando a performance ocorre acertadamente, em tom que leve à plenitude da compreensão dos saberes compartilhados com os alunos.

Ao considerar que a voz se incumbe de apresentar a nossa personalidade, e, ao levar em conta que é, também, responsável por consolidar a nossa idiossincrasia construtora de processos que nos identificam com a coletividade, pode-se ponderar que, se não formos cautelosos e prudentes quanto ao uso da voz, poder-se-á encontrar um caminho tortuoso que leve ao anonimato, ou seja, um processo que nos rotule como indigentes, já que não exerceremos nossa capacidade de usar a voz integralmente, com legitimidade. A forma como lidamos com a nossa voz mostra a nossa forma de compreender, estar e experenciar o mundo, evidencia inclusive como é que lidamos com as crises que nos assolam.

Tendo em vista o professor que canta em atividades de educação musical, ao evidenciar que a voz e canto são elementos indissociáveis, as contingências para que as performances sejam afetadas e danosas, são potencialmente iminentes.

Espera-se que, ao findar esse processo pandêmico, a ação performática da voz do professor que canta seja reestabelecido e ressignificada, e que se possa aproveitar dos aprendizados consolidados nesses dias complexos, e colocar em prática a efetiva utilização da voz e sua capacidade performática. A expectativa é que no retorno da normalidade o professor possa aprimorar a sua competência comunicativa, aperfeiçoar sua disposição didática e atentarse aos devidos cuidados referente à saúde vocal. É necessário investir continuamente no desenvolvimento vocal pessoal, para que se possa trabalhar com competência com a voz do outro.

Por fim, observa-se que neste momento de pandemia, as reflexões referentes ao uso da voz pelos professores que a utilizam como instrumento de trabalho são urgentes e 
imprescindíveis. Não se quer dizer que em momentos anteriores o olhar para a voz deveria ser, ou era minimizado. Porém, os tempos atuais trazem dispositivos universais que pelo seu próprio modo operante acabam interferindo diretamente nos processos do uso da voz, dentre eles, o que mais se destaca é a máscara que, mais do que tampar as nossas bocas, emudecem nossas vozes e silenciam nossas performances.

\section{Referências}

BEHLAU, M. (org.). Voz: o livro do especialista. 2 ed. Rio de Janeiro: Revinter, 2005.

BEHLAU, Mara; PONTES, Paulo; MORETI, Felipe. Higiene vocal: cuidando da voz. 5 ed. Rio de Janeiro: Revinter, 2017.

BORDELOIS, Ivonne. La palavra amenazada. Buenos Aires: Libros del Zorzal, 2003.

CAVARERO, Adriana. Vozes Plurais. Trad. Barbeitas, F. Belo Horizonte: Editora UFMG, 2011.

DAVINI, Silvia A. Voz e palavra - música e ato. In: MATOS, Cláudia N.; TRAVASSOS, Elizabeth; MEDEIROS, Fernanda T. de (orgs.). Palavra cantada: ensaios sobre poesia, música e voz. Rio de Janeiro: 7Letras, 2008, p. 307-315.

HUCHE, François; ALLALI, André. A voz: Anatomia e Fisiologia dos Órgãos da Voz e da Fala. Porto Alegre: Artmed, 2005.

ISAACS, Alan; MARTIN, Elizabeth. Dicionário de Música. Tradução de Álvaro Cabral. Rio de Janeiro: Zahar Editores, 1985.

MIGUEL, Fabio. Registro vocal: uma abordagem conceitual. Ouvirouver, Uberlândia, v. 8 n. 1-2 p. 2635, 2012a. Disponível em: http://www.seer.ufu.br/index.php/ouvirouver/article/view/28088. Acesso em julho de 2021.

MIGUEL, Fabio. Paisagem sonora: um estudo da voz humana como símbolo sonoro. Tese de doutorado defendida no programa de pós-graduação em Música do Instituto de Artes da UNESP. Orientadora: Profa. Dra. Marisa T. Fonterrada. São Paulo, 2012b.

MINTO, Lalo Watanabe. Pandemia e Universidade Pública: Educação, ensino e condições de trabalho. Live promovida pela ADUNESP (Associação dos Docentes da UNESP) em 05/06/2020. Disponível em: https://www.youtube.com/watch?v=7CKjN2vp5EY\&feature=youtu.be.

MOSCOVICI, Serge. Representações Sociais: investigações em psicologia social. Tradução de Pedrinho A. Quareschi. 5 ed. Vozes, Petrópolis, Rio de Janeiro, 2007.

PAULA, Joaquim de. Jogos Musicais: Recreação, Socialização, Musicalização. 1 ed. Petrópolis (RJ): J. de Paula, 2009.

PEREIRA, Marcia Maracajá P. Ensino de Literatura em cena: a performance literária da poesia na sala de aula. Revista Leitura, v. 2, n. 54, Jul/Dez 2014, p. 81-96. Disponível em: file://C:/Users/Maestro\%20Marlon/Downloads/2214-8374-2-PB.pdf. Acesso em: 15 Jul 2020. 
PINHO, Silvia M. Rebelo. Manual de higiene vocal para profissionais da voz. 3 ed. Carapicuíba, São Paulo: Pró-fono, 2002.

PINHO, Sílvia M. Rebelo; PONTES, Paulo. Músculos intrinsecos das laringe e dinâmica vocal. Rio de Janeiro: Revinter, 2008.

RODRIGUES, Adriana; CONDE, Cecília; NOGUEIRA, Marcos. Sons \& Expressões: a música na educação básica. Rio de Janeiro: Rovello, 2013.

SCHAFER, Murray R. A afinação do mundo. Tradução de Maria T. de O. Fonterrada. 2. ed. São Paulo: Ed. UNESP, 2011a.

SCHAFER, Murray R. O Ouvido Pensante. Tradução de Maria T. de O. Fonterrada. 2. ed. São Paulo: Ed. UNESP, 2011b.

SPECHT, Ana Cláudia; BUNDCHEN, Denise Sant'Anna. A atividade de apreciação na construção do cantar. In: BEYER, E.; KEBACH, P. (Org.). Pedagogia da Música: experiências de apreciação musical. 2. ed. Porto Alegre: Mediação, 2012.

SUNDEBERG, Johan. The silence of the singing voice. Illinois: Northern Illinois University Press: 1987.

VILAS, Paula C. Vozes entre festas: a performance vocal, da etnografia à cena. In: MATOS, Cláudia Neiva; TRAVASSOS, Elizabeth; MEDEIROS, Fernanda T. de (org.). Palavra cantada: ensaios sobre poesia, música e voz. Rio de Janeiro: 7Letras, 2008, p. 15- 40.

ZAGONEL, Bernadete. Brincando com música na sala de aula: jogos de criação musical usando a voz, o corpo e o movimento. Curitiba: Ibpex, 2011.

ZUMTHOR, Paul. Performance, recepção, leitura. Tradução de Jerusa P. Ferreira e Suely Fenerich. 2 ed. São Paulo: Cosac Naify, 2007.

ZUMTHOR, Paul. Performance, recepção, leitura. Tradução de Jerusa P. Ferreira e Suely Fenerich. São Paulo: EDUC, 2000. 